\title{
Central hypoventilation in a seven year old child following pertussis treated with negative pressure ventilation
}

\author{
D.L. Russell-Jones, ${ }^{1}$ D.F. Treacher, ${ }^{2}$ H.M. Lenicker, ${ }^{3}$ M. Tashanov ${ }^{3}$ and G.T. \\ Spencer ${ }^{1}$
}

\begin{abstract}
${ }^{1}$ Phipps Respiratory Unit, South Western Hospital, Landor Road, London SW9, ${ }^{2}$ Intensive Care Unit, St Thomas's Hospital London SE1 7EH, UK and ${ }^{3}$ Department of Paediatrics, St. Lukes Hospital, G-Mangia, Malta

Summary: We report the case of a 7 year old girl who developed central hypoventilation following pertussis and who was treated by negative pressure ventilation using a new portable tank respirator. We believe this is the first reported case of central hypoventilation following pertussis successfully treated by intermittent negative pressure ventilation.
\end{abstract}

\section{Introduction}

Treatment of chronic hypoventilation is difficult and numerous techniques have been employed to assist ventilation. ${ }^{1-5}$ Body type negative pressure ventilators first described in $1929^{\prime}$ and used extensively in the polio epidemic of the 1950s have recently achieved renewed popularity. The body, excluding the head, is placed in a tank with free communication of the lungs via trachea and oropharynx to the external atmosphere. The pressure surrounding the body within the tank is altered and air is sucked into and expelled from the lungs allowing gas exchange. We report the successful use of a new portable tank respirator in a 7 year old with central hypoventilation, following whooping cough.

\section{Case report}

A 7 year old Maltese girl developed a cough and began to whoop. She deteriorated over the next 2 weeks and required admission to hospital. At birth following a normal pregnancy she weighed $3.6 \mathrm{~kg}$ and her subsequent development was normal. Four months before presentation she had developed measles complicated by bronchopneumonia from which she made a complete recovery.

On admission to hospital in Malta she was drowsy and centrally cyanosed with clinical and radiological signs of a right sided pneumonia. Arterial blood gases breathing air showed an arterial oxygen tension $\left(\mathrm{PaO}_{2}\right.$ of $36 \mathrm{mmHg}(4.8 \mathrm{kPa})$ and carbon dioxide tension $\left(\mathrm{PaCO}_{2}\right)$ of $70 \mathrm{mmHg}(9.3 \mathrm{kPa})$. A diagnosis of whooping cough with pneumonia was made. She was treated in an oxygen tent but deteriorated and required artificial ventilation for 5 days. The pneumonia res-

Correspondence: G.T. Spencer F.F.A.R.C.S., O.B.E.

Accepted: 10 April 1989 ponded to treatment with antibiotics and physiotherapy. Attempts at weaning her off the ventilator were made but $\mathrm{PaCO}_{2}$ remained high, ranging from $70 \mathrm{mmHg}(9.3 \mathrm{kPa})$ when awake to $100 \mathrm{mmHg}$ $(13.3 \mathrm{kPa})$ when asleep. Lumbar puncture, computed tomographic (CT) scan of the head and an edrophonium test were normal but an electro encephalogram (EEG) showed diffuse changes com 8 patible with encephalitis. Four weeks after admissio she remained drowsy and dependent on artificiab ventilation.

She was referred to the Respiratory Unit at the South Western Hospital, London. On arrival she was cyanosed with a coarse flapping tremor and although drowsy was orientated for both time and place. There was a mild global weakness with a waddling gait but no abnormalities were found on physical examination and respiratory movements were normal to volitional stimuli.

\section{Management}

She was placed in a Cape Warwick portable tank respirator and the machine set to provide normal ventilation. During the next week she became more alert and the physical signs resolved. While awake she maintained adequate spontaneous respiration but she remained dependent on the tank respirator at night. The initial EEG when she was hypercapnoeic $\left(\mathrm{PaCO}_{2}\right.$ $=70 \mathrm{mmHg}, 9.3 \mathrm{kPa}$ ) was grossly abnormal with widespread slow wave activity. After 2 weeks continuously in the tank and 4 weeks treatment with nocturnal negative pressure tank ventilation there was a marked improvement in the EEG but it still remained abnormal, compatible with encephalitis. A high resolution CT scan was normal.

Two weeks after admission a formal overnight sleep 
study was performed with the patient sleeping without respiratory support. Measurements of both arterial oxygen saturation $\left(\mathrm{SaO}_{2}\right)$ (BioxIII Ear Oximeter) and transcutaneous carbon dioxide tension $\left(\mathrm{PCO}_{2}\right)$ (Hewlett-Packard No 428) were made (Figure 1). The baseline $\mathrm{SaO}_{2}$ was $94 \%$ and $\mathrm{PCO}_{2} 60 \mathrm{mmHg}(7.9 \mathrm{kPa})$ indicating hypercapnoea. During sleep there were repeated periods of marked hypoventilation associated with reduction of chest and abdominal wall movement resulting in significant falls of $\mathrm{SaO}_{2}$ (minimum $72 \%$ ) and increase in $\mathrm{PCO}_{2}$ (maximum $72 \mathrm{mmHg}$ ). $\mathrm{SaO}_{2}$ was $<90 \%$ for $75 \%$ of the study period and $<85 \%$ for $40 \%$ of the study period. There were no features of upper airways obstruction and a diagnosis of central hypoventilation was made. One month later a repeat 8 hour sleep study showed significant improvement with baseline $\mathrm{SaO}_{2} 95 \%$, a normal respiratory pattern during sleep and only transient periods of oxygen desaturation with a minimum saturation of $81 \%$ and $\mathrm{SaO}_{2}$ was $>95 \%$ for $90 \%$ of the study.

Her mother stated that she was as alert and active as before the illness. However, following withdrawal of the tank respirator for 5 nights she became less active, tired and difficult to wake in the mornings. A Cape Warwick portable tank respirator was installed in her home in Malta for her use.

One year after presentation she continues to sleep in the tank but is leading a normal life and is progressing well at school. Although she recently managed without respiratory support for a week without becoming symptomatic, serial blood gases demonstrated a progressive hypercapnoea with $\mathrm{PaCO}_{2}$ rising to $60 \mathrm{mmHg}$ $(8 \mathrm{kPa})$ when awake and $66 \mathrm{mmHg}(8.8 \mathrm{kPa})$ during sleep.

\section{Discussion}

It seems likely that the central hypoventilation was a sequel to pertussis infection which produced a lesion in or near the respiratory centre of the brain stem. The central hypoventilation although present during the day (abnormal blood gases and baseline $\mathrm{PaCO}_{2}$ on the sleep study when awake) was more marked when asleep with periods of severe hypoxia and hypercapnoea (Figure 1). This was confirmed by the favourable response to assisted ventilation at night. When the ventilation was withdrawn the central hypoventilation produced progressive hypercapnoea both during the day and night accompanied by a deterioration in the clinical state.

A great variety of neurological complications have been described following pertussis infection including convulsions, hemiplegia, paraplegia, deafness, blindness, aphasia and impaired intelligence. ${ }^{6,7}$ The incidence of reported cerebral complications varies widely among reviews but it appears to have fallen greatly during this century. ${ }^{6-8}$ Neurological complications most commonly occur when pertussis is contracted in the first 3 years of life. ${ }^{1,6}$

In similar situations of chronic hypoventilation other forms of ventilatory support have been tried. Diaphragmatic pacing until recently has met with little success in children., ${ }^{2,3}$ Positive pressure ventilation either via a nasal mask, mouth piece or tracheostomy has met with some success in adults. ${ }^{4}$ Increasing interest is being expressed in the nasal mask variety, although in its current form it has never been successfully tried in children. Our patient found anything attached to her face impossible to tolerate but she tolerated the negative pressure ventilator well.

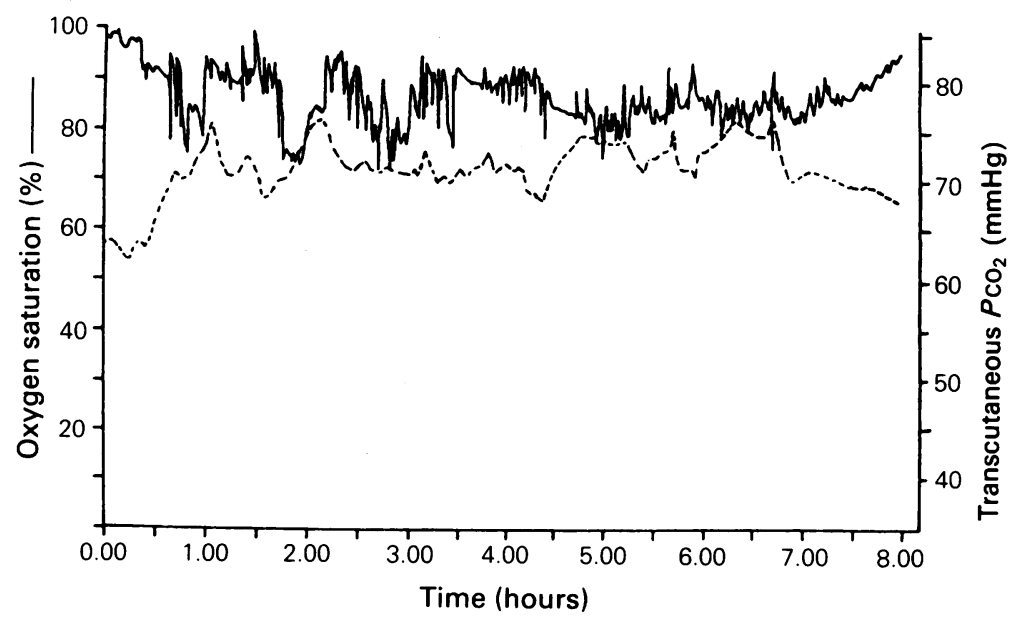

Figure 1 Initial sleep study performed 2 weeks after admission. 
This new portable tank respirator has advantages over other forms of assisted ventilation. It is robust, relatively unobtrusive and can be installed easily at home. Unlike previous models even a 7 year old child is able to get out of the tank unaided. A tracheostomy is not required and the mother can judge on a day to day basis whether the child requires assisted ventilation that night. By day the patient can lead a normal life. The tank can also accommodate growth without modification.

We believe that this is the first report of central hypoventilation following childhood whooping cough

\section{References}

1. Drinker, P., Charles, F. \& McKhann, M.D. The use of a new apparatus for the prolonged administration of artificial respiration. $J A M A$ 1929, 92: 1658-1660.

2. Glenn, W.W.L., Hollcomb, W.G., Mclaughlin, A.J., O'Hare, J.M., Hogan, J.F. \& Yasuda, R. Total ventilation support in a quadriplegic patient with radiofrequency electrophrenic respiration. $N$ Engl J Med 1972, 286: 513-516.

3. Garrido, H., Mazira, J., Gutierrez, P., Gonzalez, E., Rivas, J. \& Madrazo, J. Continuous respiratory support in quadriplegic children by bilateral phrenic nerve stimulation. Thorax. 1987, 42: 573-577.

4. Ellis, E.R., Bye, P.T.P., Bruderer, J.W. \& Sullivan, C.E. Treatment of respiratory failure during sleep in patients with neuromuscular disease. Am Rev Respir Dis 1987, 135: $148-152$. successfully treated with intermittent negative pressure ventilation.

\section{Acknowledgements}

We would like to thank Dr N. Carroll and Dr M. Branthwaite of the Brompton Hospital for performing the initial sleep study and Dr R. Parascandalo for his help in Malta.

This new portable tank respirator was designed for home use by Cape Warwick Ltd with financial assistance from the DHSS.

5. Vella, L.M., Hewitt, P.B., Jones, R.M. \& Adams, A.P. ㅎ Sleep apnoea following cervical cord surgery. Anaesthesia 1984, 39: 108-112.

6. Litak, A.M., Gibel, H., Rosenthal S. \& Rosenblatt, P. Cerebral complications in pertussis. $J$ Pediatr 1948, 32: 357-379.

7. Berg, J.M. Neurological sequelae of pertussis with particular reference to mental defect. Arch Dis Child 1959. 34: 322-324.

8. Davies, L., Burstyn, D \& Manciarh, C. Pertussis encephalopathy with a normal brain biopsy and elevate lymphocytosis-promoting factor antibodies. Pediato Infect Dis 1984, 3: 448-451. 